\title{
Health Status, Adherence with Health Recommendations, Self-Efficacy and Social Support in Patients with Rheumatoid Arthritis
}

\author{
Erik Taal, MA, Johannes J. Rasker, MD, Erwin R. Seydel, PhD \\ and Oene Wiegman, $\mathrm{PhD}$
}

Department of Psychology, University of Twente, P.O. Box 217, 7500 AE Enschede (Netherlands)

\begin{abstract}
A study was performed in 86 patients with rheumatoid arthritis (RA) to assess their health problems, the problems they experience in adhering to health recommendations and the relationships of these problems with self-efficacy and social support. Feeling dependent, disability and pain were the most important health related problems. The results showed self-efficacy to be related to the subjective experience of health status as measured by DUTCH-AIMS. Social emotional support was not related to health status, and contrary to what we expected social instrumental support was positively related to health status. The majority of the patients (55\%) experienced adherence problems with health recommendations. These problems were not related to functional incapacity, pain or other aspects of health status but to the patient's self-efficacy expectations about coping with arthritis. Our conclusion is that to improve the self-management of disability and pain and adherence to health recommendations, patient education should be aimed at strengthening self-efficacy expectations in which social emotional support might be a motivating factor.
\end{abstract}

Key words: Rheumatoid arthritis; Selfefficacy; Health status; Social support; Adherence.

\section{Introduction}

Rheumatoid arthritis (RA) is a chronic, disabling disease characterized by an unpredictable course with periods of exacerbation and remission of disease activity (Rasker and Cosh, 1987). It can have a great impact on the quality of life. The disease may affect not only physical functioning but also psychological and social aspects (Anderson et al., 1985).

Most important problems for RA patients are functional disability, pain and loss of independence (Anderson et al., 1985; Cornelissen et al., 1988; Lorig et al., 1984; Rasker et al., 1984). Also psychological problems like depression and anxiety are often mentioned as consequences of RA (Anderson et al., 1985). In addition, the disease can lead to major changes in family and marital functioning and social activities (Anderson et al., 1985; Cornelissen et al., 1988; Liang et al., 1984; Meenan et al., 1981; Rasker et al., 1984). Patients can also have considerable financial problems due to work disability and the additional direct and indirect costs they have to make that are not covered by insurance (Meenan et al., 1978; Meenan et al., 1981; Rasker et al., 1984). The adherence to the 
medical treatment and lifestyle recommendations can be problematic to the patient (Bradley, 1989). Since RA cannot be cured, the goals of treatment and management are the relief of pain, the prevention of joint destruction, and the preservation or improvement of the patient's functioning. Treatment is usually a regimen of rest, exercise and medication (Ruddy, 1985). Estimates of adherence in RA patients have ranged from 30 to $78 \%$ for medication and from 25 to $65 \%$ regarding physical therapy and home exercises (Bradley, 1989; Feinberg, 1988). An important aspect of adherence in RA is that the treatment regimen must be adjusted to daily disease activity. This presupposes adequate treatment and support by health professionals. Also the patient has an important role in the management of the disease. The patient must learn to adjust rest, exercise and medication to the, sometimes even daily, varying disease activity. Patient education can help patients in making the right decisions about adjustments in their treatment regimen and in attaining the necessary self-management behaviors (Lorig et al., 1987).

In a review of arthritis patient education studies Lorig, Konkol and Gonzalez (1987) concluded that patient education can be effective in changing knowledge, behaviors and health status. They also stated that future studies should focus on health status outcomes, and on defining mechanisms by which effects are achieved. According to social learning theory an important mechanism in behavior change is the concept of self-efficacy (Bandura, 1986). Bandura's social learning theory states that people's perceptions of their capabilities affect their behavior, motivation, thought patterns and their emotional reactions in critical situations (Bandura, 1986). Self-efficacy can be defined as a person's conviction that he or she can successfully execute the behavior required to produce a certain desired outcome.

In relation to $\mathrm{RA}$, self-efficacy expectations seem to be of major importance. The unpre- dictable course and the varying disease activity may cause patients to view their disease as uncontrollable leading to lower self-efficacy expectations about the self-management of the consequences of the disease (Bradley et al., 1984). The fecling that they cannot control their disease may cause patients to experience anxiety and depression (Bandura, 1986). This, in turn, can lead to increased perceptions of pain and reduced efforts to cope with the consequences of the disease or engage in daily activities. As a consequence, health status will further deteriorate. Psychosocial interventions aimed at strengthening self-efficacy expectations about managing pain and other physical or psychosocial consequences of RA could lead to better self-management and eventually a better health status.

Several studies have shown associations between self-efficacy expectations and health status in arthritis patients and that changes in self-efficacy are related to changes in health status. In arthritis patients significant relations were found between self-efficacy and pain and disability four weeks later (Shoor and Holman, 1984). Lorig et al. (1989) developed an instrument to measure the perceived self-efficacy of people with arthritis. They found significant associations between self-efficacy and both present and future (four months later) health status (pain, depression, functional disability). Furthermore, changes in self-efficacy were related to changes in health status. O'Leary et al. (1988) showed that strengthening of self-efficacy expectations in RA patients through a cognitivebehavioral intervention was related to a reduction of pain and functional impairment. Patients with higher self-efficacy expectations also were less depressed, less stressed and slept better (O'Leary et al., 1988).

Not only the patient's own self-efficacy expectations are an important factor in health behavior and adherence to health guidelines. Also the perceptions of the patient's spouse or other closely related persons about the capacities of the patient to cope with the con- 
sequences of the disease, expressing itself in social support, may be important. In cardiac rehabilitation it has been shown that the spouse plays a significant role in a patient's recovery, either by encouraging physical activity or by communicating worry or concern about the patient's efforts, depending on the spouse's perception of the physical capacities of the patient (Taylor et al., 1985). It is to be expected that in RA the spouse's perceptions of the capacities of the patient to cope with the consequences of the disease will also be important because the spouse often adopts the role of carer for the patient. Low perceptions of the capacities of the patient by the spouse will lead to patronizing behavior, and high perceptions of the patient's capacities by the spouse will lead to supportive behavior. Significant relationships have been found between social support and health status in arthritis patients (Affleck et al., 1988; Weinberger et al., 1990; Goodenow et al., 1990; Krol et al., this issue). For instance, Goodenow et al. (1990) found significant relations between the quality of social support and social and psychological functioning in women with RA.

Here we will report on a study conducted in the process of developing an educational program for RA patients. Before devising a patient education program one has to have insight in the health problems patients are confronted with and determinants of these problems (Green and Kreuter, 1991). The purpose of this study was (a) to assess the most important health related problems of RA patients, and (b) to investigate the relationships between self-efficacy, perceived social support and health problems.

\section{Methods}

\section{Patients}

Participants in the study were patients with definite or classical RA (Ropes et al., 1958). Four rheumatologists each asked 25 consecutive outpatients, who came for a control visit, to take part in the study. In this study the subjects were first interviewed in their homes, and four weeks later they received a questionnaire by mail.

Of the 100 selected patients, 86 were interviewed. Fourteen patients were not interviewed because they could not be reached, as yet refused to take part, or were too ill. This group of 14 patients did not differ significantly from the group of interviewed patients regarding age, sex, diagnosis (definite or classical RA) and functional classification. The 86 patients that were interviewed in their homes were sent a questionnaire by mail four weeks after the interview. This mailed questionnaire was completed and returned by 73 patients.

Of the 86 patients that were interviewed in their homes $61(71 \%)$ were female. Mean age was 60 years, and the average disease duration was 14 years. Each patient's functional level was assessed by the rheumatologist according to the ARA classification (Steinbröcker et al., 1949). Most patients were assessed to be Class II $(36 \%)$ or III $(43 \%)$. Only $12 \%$ were Class I and $9 \%$ Class IV.

\section{The interview}

In the semi-structured interview, data were obtained on the following topics.

Main disease problems. Patients were asked to state in their own words what it means to them to have RA. Patients could state a maximum of three problems. Subsequently patients were presented a number of problems that could be of significant importance to RA patients, according to the consulted literature (Anderson et al., 1985; Banwell and Ziebell, 1985; Cornelissen et al., 1988; Lorig et al., 1984; Rasker et al., 1984). With each problem patients were asked to indicate whether they experienced this as problematic.

Health recommendations. Patients were asked whether they had received health recommendations about matters like medication, adjustments in daily activities and physical therapy by health professionals. We also assessed whether they experienced pro- 
blems in adhering with these recommendations and why. A "problem-index" was calculated ranging from 0 (no problems) to 1 (problems with every recommendation).

Social support. Two aspects of social support have been measured, perceived emotional support and perceived instrumental support. A scale of four items was used to assess perceived emotional support: "How much support do you get in coping with your disease from your spouse/your children/other relatives/your friends?"'. The items were rated on five-point scales with endpoints very little and very much. Cronbach's $\alpha$-coefficient was $0.70(n=41)$. The item-total correlations were all higher then 0.40 . Because some patients didn't have a spouse $(n=19)$ or didn't have children $(n=13)$ a mean score for the scale was calculated ranging from 1 (very little perceived social support) to 5 (very much perceived social support) when at least two items were applicable.

Perceived instrumental support was measured with one five-point scale: "How much help do you get from people close to you?" ("very little" to "very much").

Arthritis self-efficacy. Self-efficacy expectations were measured with nine five-point rating scales. Answers ranged from totally disagree to totally agree. Examples of items are:

- I am certain that I can reduce my arthritis pain without taking extra medication.

- I am certain I can control my arthritis in such a way so that I can do the things I enjoy doing.

Internal consistency of the self-efficacy scale was satisfactory (Cronbach's $\alpha=0.80$, $n=82$ ). Item-total correlations ranged from 0.30 to 0.61 . For the scale a mean score has been calculated ranging from 1 (very low selfefficacy) to 5 (very high self-efficacy).

\section{The mailed questionnaire}

The mailed questionnaire contained the DUTCH-AIMS, a Dutch version of the Arthritis Impact Measurement Scales (Meenan et al., 1980; Meenan et al., 1982; Taal et al.,
1989). The first 43 questions of the DUTCHAIMS measure nine aspects of health status: mobility, physical activity, dexterity, household activities, social activities, activities of daily living (ADL), pain, depression and anxiety. Furthermore the DUTCH-AIMS include the scale Arthritis Impact: a horizontal visual analog scale for glohal assessment of the effect of arthritis on overall well-being. The DUTCH-AIMS scores reflect health status on scales from $0-10$ where 0 means good health status and 10 bad health status. In this study the DUTCH-AIMS showed satisfactory internal consistency and validity, with the exception of the scale Social Activities. These results have been published elsewhere (Taal et al., 1989).

\section{Laboratory measures}

Data were collected from patient records on haemoglobin count ( $\mathrm{Hb})$ and erythrocyte sedimentation rate (ESR). Since ESR and $\mathrm{Hb}$ may vary with disease activity, these data were used only if they had been obtained in the period from four weeks before the interview till four weeks after the completion of the mailed questionnaire. Values of $\mathrm{Hb}$ were available in 63 patients $(73 \%)$ and values of ESR in 65 patients $(76 \%)$.

\section{Results}

\section{Main disease problems}

Table 1 shows the main disease problems (maximum three problems) the RA patients mentioned. Functional disability (not being able to do things, mobility restrictions), feeling dependent and pain seem to be the most important problems. Psychological, family and marital, social, and financial problems are not very often mentioned. It is remarkable that 10 patients stated that they find the disease hard to accept while 15 patients, on the contrary, state they have learned to live with their disease.

Patients were also shown a list of problcms and were asked whether they perceived these 
Table 1. 'What does it mean to have rheumatoid arthritis?' Main disease problems of 86 RA patients ${ }^{\mathrm{a}}$.

\begin{tabular}{llc}
\hline Response & \multicolumn{2}{l}{ Number of patients giving response } \\
\cline { 2 - 3 } & Absolute & Percentage \\
\hline Not being able to do things ${ }^{\mathrm{b}}$ & 44 & 51 \\
Feeling dependent & 20 & 23 \\
Pain & 17 & 20 \\
I have learned to live with my disease & 15 & 17 \\
Mobility restrictions & 12 & 14 \\
Disease is hard to accept & 10 & 12 \\
Terrible disease & 9 & 11 \\
Fatiguc & 4 & 5 \\
Incomprehension $^{\text {Other responses }}{ }^{c}$ & 4 & 5 \\
& 16 & 19
\end{tabular}

${ }^{\text {a } P a t i e n t s ~ c o u l d ~ s t a t e ~ a ~ m a x i m u m ~ o f ~ t h r e e ~ p r o b l e m s . ~}$

${ }^{b}$ Responses are ranked from most mentioned to least mentioned.

${ }^{\mathrm{c}}$ Responses given by only one or two patients are included in the category Other responses.

problems as problematic too (Table 2). Again we see that functional disability, pain and feeling dependent are important health problems for RA patients. Fatigue and other physical complaints are now also assessed as problematic by many patients. It is striking that patients do not often mention psychological problems spontaneously, while

Table 2. Number of patients that see presented health problems as problematic.

\begin{tabular}{lll}
\hline Response & Number of patients that see problem as problematic \\
\cline { 2 - 3 } & Absolute & Percentage \\
\hline Not being able to do things & 77 & 90 \\
Mobility restrictions & 75 & 87 \\
Pain & 74 & 86 \\
Fatigue & 71 & 83 \\
Other physical complaints & 62 & 72 \\
Feeling dependent & 58 & 67 \\
Uncertainty about future course of disease & 42 & 49 \\
Incomprehension of family members & 33 & 38 \\
Future has fallen apart & 31 & 36 \\
Loss of social contacts & 29 & 34 \\
Feelings of anxiety, fear, depression & 29 & 34 \\
Sorrow and tension in family relationships & 27 & 31 \\
Loss of self-esteem & 27 & 31 \\
The feeling to have lost control of one's own life & 25 & 29 \\
Loneliness & 19 & 22 \\
Financial problems & 14 & 16 \\
Incomprehension of colleagues from work & & 5
\end{tabular}

${ }^{a}$ Not applicable for 73 patients because they don't have a job. 
now about $30 \%$ of patients state having such problems. The most often mentioned psychological problem is uncertainty about the future course of the disease.

\section{DUTCH-AIMS}

Table 3 shows the mean scores on the DUTCH-AIMS and correlations between the scores on the various functional, social and psychological scales. Measured by DUTCHAIMS we see that functional problems (physical activity, dexterity) and pain are most important. This is comparable to the problems mentioned in the interview.

The various aspects of health status as measured by DUTCH-AIMS are highly correlated. An exception is Social Activities; this scale has only significant correlations with Depression and Arthritis Impact.

\section{Social support, arthritis self-efficacy and health outcomes}

The mean score on the emotional support scale was $3.4($ S.D. $=1.0)$. Fourteen patients $(16.3 \%)$ indicated that they get very little or fairly little emotional support. The mean score on the instrumental support scale was 3.7 (S.D. = 1.4). The mean score on the arthritis self-efficacy scale was 3.2 (S.D. $=1.0$ ). There are no significant correlations between emotional support, instrumental support and arthritis self-efficacy. Table 4 shows correlations of self-efficacy, emotional and instrumental support with self-reported health status (DUTCH-AIMS), ARA functional classification by physician and laboratory measures of haemoglobin count $(\mathrm{Hb})$ and erythrocyte sedimentation rate (ESR).

Except for Activities of Daily Living and Social Activities, arthritis self-efficacy shows significant negative correlations with selfreported health status as measured by DUTCH-AIMS and with ESR, and a positive correlation with $\mathrm{Hb}$. Arthritis self-efficacy is not significantly correlated with the ARA functional classification by physician. Because self-efficacy is significantly correlated with disease activity (Hb, ESR) we also calculated partial correlations between selfefficacy and self-reported health status controlling for laboratory measures of $\mathrm{Hb}$ and ESR. We find significant partial correlations of arthritis self-efficacy with Physical Activities, Dexterity, Pain, Depression, Anxiety and Arthritis Impact. Partial correlations with Mobility and Household Activities are not significant. So, the significant correlations between self-reported health status and selfefficacy cannot be explained by the significant

Table 3. DUTCH-AIMS: mean scores with standard deviations (in parentheses) and Spearman Rho correlations between scales.

\begin{tabular}{|c|c|c|c|c|c|c|c|c|c|c|c|c|}
\hline Scale & & Mean & (S.D.) & 1 & 2 & 3 & 4 & 5 & 6 & 7 & 8 & 9 \\
\hline 1. & Mobility & 2.6 & $(2.8)$ & & & & & & & & & \\
\hline 2. & Physical Activity & 6.6 & (2.7) & $0.66 \ddagger$ & & & & & & & & \\
\hline 3. & Dexterity & 5.5 & $(3.5)$ & $0.62 \ddagger$ & $0.60 \ddagger$ & & & & & & & \\
\hline 4. & Household Activities & 2.9 & (2.4) & $0.72 \ddagger$ & $0.66 \ddagger$ & $0.67 \ddagger$ & & & & & & \\
\hline 5. & $\mathrm{ADL}$ & 1.7 & $(2.2)$ & $0.68 \ddagger$ & $0.54 \ddagger$ & $0.64 \ddagger$ & $0.71 \ddagger$ & & & & & \\
\hline & Social Activities & 4.5 & (1.8) & 0.13 & 0.18 & 0.15 & 0.13 & 0.20 & & & & \\
\hline 7. & Pain & 5.9 & $(2.1)$ & $0.41 \ddagger$ & $0.52 \ddagger$ & $0.57 \ddagger$ & $0.36 \dagger$ & $0.26^{*}$ & 0.08 & & & \\
\hline 8. & Depression & 3.4 & (1.9) & $0.50 \ddagger$ & $0.54 \ddagger$ & $0.55 \ddagger$ & $0.51 \ddagger$ & $0.36 \ddagger$ & $0.24 *$ & $0.61 \ddagger$ & & \\
\hline 9. & Anxiety & 4.2 & (2.1) & $0.41 \ddagger$ & $0.42 \ddagger$ & $0.44 \ddagger$ & $0.43 \ddagger$ & $0.26^{*}$ & 0.18 & $0.50 \ddagger$ & $0.80 \ddagger$ & \\
\hline 10. & Arthritis Impact & 5.4 & $(1.8)$ & $0.51 \ddagger$ & $0.58 \ddagger$ & $0.55 \ddagger$ & $0.44 \ddagger$ & $0.45 \ddagger$ & $0.25^{*}$ & $0.63 \ddagger$ & $0.57 \ddagger$ & $0.38 \ddagger$ \\
\hline
\end{tabular}

${ }^{*} P<0.05 ; \uparrow P<0.01 ; \ddagger P<0.001$. 
Table 4. Spearman Rho Correlations of arthritis self-efficacy, emotional and instrumental support with health status (DUTCH-AIMS), ARA functional class, haemoglobin count $(\mathrm{Hb})$ and erythrocyte sedimentation rate (ESR).

\begin{tabular}{llcc}
\hline & $\begin{array}{l}\text { Arthritis } \\
\text { self-efficacy }\end{array}$ & $\begin{array}{l}\text { Emotional } \\
\text { support }\end{array}$ & $\begin{array}{l}\text { Instrumental } \\
\text { support }\end{array}$ \\
\hline DUTCH-AIMS & & & \\
Mobility & $-0.24^{*}$ & 0.19 & $0.39 \ddagger$ \\
Physical Activity & $-0.30^{\dagger}$ & 0.11 & $0.21^{*}$ \\
Dexterity & $-0.43 \ddagger$ & 0.01 & $0.26^{*}$ \\
Household Activities & $-0.25^{*}$ & 0.12 & $0.38 \ddagger$ \\
ADL & -0.14 & 0.17 & $0.49 \ddagger$ \\
Social Activities & 0.00 & -0.14 & -0.00 \\
Pain & $-0.44 \ddagger$ & -0.01 & -0.03 \\
Depression & $-0.56 \ddagger$ & -0.15 & 0.08 \\
Anxiety & $-0.55 \ddagger$ & -0.17 & 0.03 \\
Arthritis Impact & $-0.46 \ddagger$ & 0.05 & $0.31 \dagger$ \\
ARA functional class & -0.12 & -0.06 & 0.16 \\
Laboratory measures & & & $-0.29^{*}$ \\
Hb & $0.24^{*}$ & -0.02 & $0.27^{*}$ \\
ESR & $-0.25^{*}$ & 0.13 & \\
\hline
\end{tabular}

${ }^{*} P<0.05 ; \nmid P<0.01 ; \ddagger P<0.001$.

correlations between self-efficacy and disease activity (Hb, ESR).

We also calculated partial correlations of self-efficacy with $\mathrm{Hb}$ and ESR controlling for self-reported health status (scores on all 10 scales of DUTCH-AIMS). These partial correlations are not significant. This means that the correlations of self-efficacy with $\mathrm{Hb}$ and ESR can be explained by the correlations with self-reported health status. There are no significant correlations of emotional support with self-reported health status, ARA functional class, $\mathrm{Hb}$ and ESR.

Contrary to our expectations there are significant positive correlations of instrumental support with self-reported functional health status (Mobility, Physical Activities, Dexterity, Household Activities, ADL), Arthritis Impact and ESR, and a negative correlation with $\mathrm{Hb}$. There are no other significant correlations. We find significant partial correlations between instrumental support and Mobility,
Household Activities and ADL controlling for $\mathrm{Hb}$ and ESR. For Physical Activities, Dexterity and Arthritis Impact partial correlations are not significant. Partial correlations between instrumental support and $\mathrm{Hb}$ and ESR controlling for self-reported health status are not significant.

Problems with adhering to health recommendations

Table 5 shows about which health related matters patients received recommendations and whether they had problems in adhering with these recommendations. Most recommendations were given about joint protection, medication, rest and physical therapy. Fortyseven patients $(55 \%)$ did have problems in adhering with at least one health recommendation. Most problems were experienced with adhering to recommendations about joint protection, adjustments in household activities, rest and exercises. The most often mentioned reason for having problems in 
Table 5. Health recommendations received by $86 \mathrm{RA}$ patients from health professionals and number of patients who had problems in adhering to recommendations

\begin{tabular}{lllll}
\hline Recommendation & \multicolumn{2}{l}{ No. of patients. } & & \\
\cline { 2 - 5 } & Received recommendation & Had problems in adhering \\
\cline { 2 - 5 } & Absolute & Percentage & Absolute & Percentage \\
\hline Joint protection & 72 & 84 & 18 & 25 \\
Medication & 71 & 83 & 5 & 7 \\
Rest & 55 & 64 & 14 & 26 \\
Physical therapy & 51 & 59 & 3 & 6 \\
Aids and self-help devices & 45 & 52 & 6 & 13 \\
Home exercises & 43 & 50 & 15 & 28 \\
Adjustments in household activities & 39 & 45 & 4 & 39 \\
Structural home adaptations & 37 & 43 & 0 & 11 \\
Diet & 13 & 15 & 1 & 0 \\
Work adaptations & 5 & 6 & & 20 \\
\hline
\end{tabular}

adhering is the perception not to be capable to implement the recommendation $(n=29)$. With joint protection this is mentioned by 10 patients, with adjustments in daily activities by 11 patients, with recommendations about rest by seven patients and with medication by one patient. Lack of motivation is given by seven patients as reason for not adhering to recommendations about home exercises. With joint protection lack of motivation is mentioned by three patients. Other reasons that are mentioned quite often are "I don't see the benefits of adhering to this recommendation" $(n=9)$, "information given by health professionals is not sufficient or inconsistent" $(n=3)$, "too painful" $(n=3)$. Four patients mention as problem with medications the negative side-effects. Other mentioned reasons for problems in adhering are mostly practical, like "I don't have the time", "worksituation", "aids have not yet been delivered" or "home adaptations are not yet realised".

Table 6 shows correlations of the mean number of problems patients have with adhering to recommendations and the ProblemIndex with health status as measured by DUTCH-AIMS, ARA functional class, labo-
Table 6. Spearman Rho Correlations of problems with adhering to health recommendations and health status (DUTCH-AIMS), ARA functional class, haemoglobin count $(\mathrm{Hb})$, erythrocyte sedimentation rate (ESR), arthritis self-efficacy and emotional and instrumental support.

\begin{tabular}{lll}
\hline & $\begin{array}{l}\text { Number of } \\
\text { problems }\end{array}$ & $\begin{array}{l}\text { Problem- } \\
\text { index }\end{array}$ \\
\hline DUTCH-AIMS & & \\
Mobility & 0.01 & -0.03 \\
Physical Activity & -0.03 & -0.05 \\
Dexterity & -0.01 & -0.05 \\
Household Activities & -0.05 & -0.03 \\
ADL & -0.11 & -0.11 \\
Social Activities & 0.07 & 0.06 \\
Pain & 0.13 & 0.07 \\
Depression & 0.13 & 0.09 \\
Anxiety & 0.08 & 0.06 \\
Arthritis Impact & 0.11 & 0.07 \\
ARA functional class & 0.14 & 0.12 \\
Laboratory measures & & \\
Hb & -0.04 & -0.07 \\
ESR & -0.09 & -0.09 \\
Arthritis self-efficacy & $-0.30 \dagger$ & $-0.26 \dagger$ \\
Emotional support & -0.09 & $-0.19^{*}$ \\
Instrumental support & $0.23^{*}$ & $0.22^{*}$ \\
\hline
\end{tabular}

${ }^{*} P<0.05 ; \dagger P<0.01$. 
ratory measures of $\mathrm{Hb}$ and ESR, Arthritis Self-Efficacy, emotional and instrumental support.

There are no significant correlations between problems with adhering to health recommendations and health status as measured by DUTCH-AIMS, ARA functional class and $\mathrm{Hb}$ and ESR. This means that having problems with adhering to health recommendations is not related to the seriousness of the disease, functional disability, pain and psychosocial problems. Especially the fact that there is no relation with functional disability is striking. The experience of problems with adhering to health recommendations cannot be explained by functional disabilities of the patient.

Self-efficacy is significantly correlated with the total number of problems with health recommendations and the problem-index. Controlling for disease activity (Hb, ESR), self-report of functional status (Mobility, Physical Activities, Dexterity, Household Activities, ADL) and pain, partial correlations between self-efficacy and total number of problems and the problem-index are still significant.

Emotional support shows to be negatively correlated with the problem-index but not with the total amount of problems experienced.

Contrary to our expectations instrumental support is positively correlated with problems with adhering to health recommendations.

\section{Discussion}

From this study we can conclude that the most important problems for RA patients are disability, feeling dependent and pain. These results are in general consistent with the findings of other studies (Brown et al., 1987; Buchanan, 1982; Chamberlain et al., 1979; Cornelissen et al., 1988; Lorig et al., 1984; Rasker et al., 1984). As in our study two other Dutch studies and two English studies found pain to be a less important problem for arthritis patients than disability and feeling dependent (Buchanan, 1982; Chamberlain et al., 1979; Cornelissen et al., 1988; Rasker et al., 1984). This is a striking difference with studies in the United States and South Africa where pain was found to be the most important problem for arthritis patients (Brown et al., 1987; Lorig et al., 1984). Also in review articles pain is often seen as the most important consequence of RA (Anderson et al., 1985; Banwell and Ziebell, 1985; Buckelew and Parker, 1989). An explanation for these differences can possibly be found in the phrasing of the questions in the various studies. For instance Lorig et al. (1984) asked patients to mention five to 10 problems. Cornelissen et al. (1988), Buchanan (1982) and Chamberlain et al. (1979) asked the patients what they felt was the main disadvantage of their disease. So, patients could state only their most important problem, while in the study by Lorig et al. patients could mention up to 10 problems. In our study patients could mention no more than three important problems. Of course pain is one of the main concerns of arthritis patients. When we asked patients explicitly whether pain was a problem to them, $86 \%$ stated that this was indeed the case. It seems that for many patients the pain itself is not their main concern, but the restrictions in daily functioning and the lack of independence, possibly for a great deal caused by their pain.

About one third of the patients in our study state having psychological problems. The most frequently mentioned problem is the uncertainty about the future course of the disease. When we look at the mean scores on DUTCH-AIMS for depression (3.35) and for anxiety (4.20) on scales ranging from 0 to 10 we might conclude that the patients in our study do not have substantial problems with depression and anxiety. Because we don't have a control group in our study of physically healthy people we cannot draw conclusions about the differences between RA patients 
and healthy people regarding depression and anxiety. In several studies elevated depression scores on scales like the MMPI have been found (Liang et al., 1984; Moos and Solomon, 1964; Spergel et al., 1978). Depression seems not to be specific to RA but is generally found in patients with chronic diseases (Cassileth et al., 1984). A problem with most studies is that scales used to measure depression contain items about somatic symptoms that can result from depression as well as from RA (Blalock et al., 1989; Callahan et al., 1991; Peck et al., 1989; Pincus et al., 1986; Pincus and Callahan, this issue). This criterion contamination can lead to elevated scores on these depression scales that may be at least partially explained by the illness itself. Despite this criterion contamination, however, it is clear that depression may be a problem in RA patients (Anderson et al., 1985; Blalock et al., 1989; Callahan et al., 1991; Peck et al., 1989; Pincus et al., 1986; Pincus and Callahan, this issue).

The various physical and psychosocial aspects of health status as measured by DUTCH-AIMS are highly correlated. An exception is Social Activities; this scale has only significant correlations with Depression and Arthritis Impact. Also, patients do not often mention social problems. In our study into the validity of the DUTCH-AIMS we found that correlations between Social Activities and other measures of health status and disease activity were generally lower compared to the other scales of the DUTCH-AIMS (Taal et al., 1989). So it may be concluded that RA patients do not seem to have many problems with social activities and these problems do not appear to be strongly related to the severity of the disease. Other Dutch studies also indicate that a decrease in social activities of the arthritic patient is not directly related to the severity of the disease. A reduction of social contacts was mainly found in patients living in cities and less in patients living in rural areas (Cornelissen et al., 1988; Rasker et al., 1984).
This study shows the importance of selfefficacy expectations in relation to health outcomes. The more RA patients view themselves capable to control their own disease (selfefficacy) the better they judge their own health status. This is independent of disease activity (Hb, ESR). Self-efficacy is not significantly correlated with ARA functional classification. The significant correlations of self-efficacy with $\mathrm{Hb}$ and ESR can be explained by the correlations with self-reported health status (DUTCH-AIMS). This means that self-efficacy is related to the subjective experience of health status but not to more objective health indicators like the classification by the rheumatologist or laboratory tests. Our results indicate that perceived selfefficacy may be a determinant of experienced health status that operates partially independently of the underlying physical condition as would be expected according to social learning theory (Bandura, 1986). Bandura (1986) states that self-efficacy is a significant determinant of performance that operates partially independently of underlying skills. For instance, in patients recovering from a heart attack it has been found that perceived self-efficacy regarding physical capability is a better predictor of resumption of an active life than cardiovascular capacity (Bandura, 1986; Ewart et al., 1983). Also in other studies with arthritis patients similar relations were found between self-efficacy and health outcomes (Lorig et al., 1989; O'Leary et al., 1988; Shoor and Holman, 1984). Because we only investigated correlational relationships, we cannot draw conclusions about the role of self-efficacy expectations in the subjective experience of health in RA patients. However, other studies have shown that growth in selfefficacy is associated with improvement in experienced health status in arthritis patients (Lorig et al., 1989; O'Leary et al., 1988).

Regarding social support we do not find any significant correlations between perceived emotional support and health outcomes, and contrary to what could be expected according 
to the literature we find positive correlations between perceived instrumental support and functional health status (Affleck et al., 1988; Goodenow et al., 1990; Weinberger et al., 1990). This means that the greater the instrumental support received, the more functionally disabled the patients are. In another Dutch study on 272 RA patients by Doeglas et al. (1992) similar relations are found between social support and functional status. They found positive relationships of problem oriented and instrumental support with functional status and negative correlations between social companionship and functional status. We agree with Doeglas et al. that we might be facing here a causality problem. It could be that instrumental support does not lead to a better functional health status, but greater functional disability evokes greater instrumental support. Another explanation could be that patients get overprotected by people close to them (Doeglas et al., 1992). Due to this overprotection they cannot carry out all the activities they are able to do and we might expect thus that greater support leads to greater disability.

A majority of the patients $(55 \%)$ in this study experience problems in adhering to health recommendations. The problems with adherence to recommendations mostly have to do with the self-management of the disease. Problems are mainly about adaptations one has to make in daily life and household activities to protect the joints, and about the performance of home exercises and the taking of rest. Other studies with arthritis patients and also studies on patients with other chronic diseases have shown that adherence to health recommendations is often lacking (Bradley, 1989; Feinberg, 1988; DiMatteo and DiNicola, 1982). According to the literature important factors that may influence adherence are the complexity of advices, a poor relationship between doctor and patient, and the interference of advices with personal beliefs, goals and expectations (Bradley, 1989; Feinberg, 1988; DiMatteo and DiNicola,
1982; Ley, 1979). Reasons mentioned for having problems seem to indicate in this study that patients often are physically incapable or see themselves as not capable (i.e. low selfefficacy) in performing the recommended health behaviors. We do not find any significant correlations of problems in adherence with functional disability, pain and other aspects of health status. But we do find significant negative correlations with self-efficacy expectations about coping with arthritis. This means that problems in adherence are not primarily caused by functional incapacity but by the patient's subjective estimates of his/her own capabilities in coping with the consequences of arthritis. This is in accordance with Bandura's social learning theory. According to Bandura (1986) perceived self-efficacy is a significant predictor of performance that operates partially independently of underlying skills.

Other reasons patients give for problems in adhering to recommendations indicate that patients sometimes are not very motivated to adhere, or that the information given by health care providers is not sufficient or inconsistent. Feinberg (1988) states in her review of adherence studies in rheumatoid arthritis that the doctor-patient relationship is probably the most important factor in adherence. The inconsistency that some patients experience in the information they receive from health care providers could point at a lack of coordination between the various health care providers. The first results of a study we recently started on coordination in the treatment of RA patients also indicate that there is a lack of coordination between health care providers in the recommendations they give (Riemsma et al., 1992). Because RA patients are confronted with several health care providers from various health professions an optimal coordination between health care providers is of crucial importance.

The amount of problems patients experienced in adhering to health recommendations are negatively correlated to perceived 
emotional support but positively correlated to perceived instrumental support. The positive correlation with instrumental support is in accordance with the positive correlations we find between instrumental support and health status. This might indicate that instrumental support can lead to non-adherence with health recommendations from health professionals. Emotional support can be a motivating factor for the patient to adhere to health recommendations as shown by the significant negative correlation between problems in adherence and perceived emotional support.

Inspection of our data shows that both selfefficacy and emotional support are important determinants of adherence problems. But because self-efficacy is higher correlated to adherence problems then emotional support (see Table 6), our conclusion is that, in accordance with our findings with regard to the subjective experience of health status, selfefficacy is the most important determinant of adherence.

\section{Implications for Patient Education}

Because most problems RA patients experience are related to disability and pain, the educational program we are developing will be mainly concerned with the management of disability and pain. How patients experience functional problems and pain depends on their self-efficacy expectations. Adherence with health recommendations is also related to the patients self-efficacy expectations. So, to improve the self-management of pain and disability and the adherence with health recommendations patient educational efforts should be aimed at strengthening the patient's self-efficacy expectations about coping with arthritis. Effective methods to increase selfefficacy are guided exercise of new skills and the setting of short-term goals in combination with feedback about accomplishments (Bandura, 1986). Another effective method is modeling (Bandura, 1986). Modeling means that patients who are successful in coping with certain problems act as models for other patients. In group education modeling can be used very effectively by having group members help each other in solving problems (Gonzalez et al., 1990).

Social emotional support can be a motivating factor for the patient to adhere to health recommendations. Therefore it is important not only to educate the patient but also the patient's spouse and other close relatives.

\section{Acknowledgements}

This study was supported by a grant from the Dutch Prevention Foundation (Praeventiefonds). We would like to thank Dr J.W.G. Jacobs, rheumatologist (Department of Rheumatology, University Hospital, Utrecht), who developed the DUTCH-AIMS, M. Numan-Remmen M.Sc. (Cross Association Twente), J. Drewes M.Sc. and P. Gho M.Sc. (Dutch National Cross Association) for their help in setting up and carrying out the study, and the rheumatologists Dr J.J.M. Festen, Dr M.W.M. Kruijsen and J.C.M. Oostveen M.Sc. for their selection and classification of the patients.

\section{References}

Affleck, G., Pfeiffer, H., Tennen, J. and Fifield, J. (1988). Social support and psychosocial adjustment to rheumatoid arthritis. Arthritis Care and Research, 1, 71-77.

Anderson, K.O., Bradley, L.A., Young, L.D., McDaniel, L.K. and Wise, C.M. (1985). Rheumatoid arthritis: review of psychological factors related to etiology, effects, and treatment. Psychological Bulletin, 98, 358-387.

Bandura, A. (1986). Social foundations of thought and action: $A$ social cognitive theory. Englewood: Prentice-Hall.

Banwell, B.F. and Ziebell, B. (1985): Psychological and Sexual Health in Rheumatic Diseases. In: W.N. Kelley, E.D. Harris, S. Ruddy, C.B. Sledge (Eds.). Textbook of Rheumatology. Vol. 1, 2nd edition. (pp. 497-511). Philadelphia: W.B. Saunders Comp.

Blalock, S.J., DeVellis, R.F., Brown, G.K. and Wallston, K.A. (1989). Validity of the center for epidemiological studies depression scale in arthritis populations. Arthritis and Rheumatism, 32, 991-997.

Bradley, L.A. (1989). Adherence with treatment regimens among adult rheumatoid arthritis patients: current status and future directions. Arthritis Care and Research, 2, 33-39. 
Bradley, L.A. (1989). Adherence with treatment regimens among adult rheumatoid arthritis patients: current status and future directions. Arthritis Care and Research, 2, 33-39.

Bradley, L.A., Young, L.D., Anderson, K.O., McDaniel, L.K., Turner, R.A. and Agudelo, C.A. (1984). Psychological approaches to the management of arthritis pain. Social Science and Medicine, 19, 1353-1360.

Brown, G.M.M., Dare, C.M., Smith, P.R. and Meyers, O.L. (1987). Important problems identified by patients with chronic arthritis. South African Medical Journal, 72, 126-128.

Buckelew, S.P. and Parker, J.C. (1989). Coping with arthritis pain - a review of the literature. Arthritis Care and Research, 2, 135-45.

Callahan, L.F., Kaplan, M.R. and Pincus, T. (1991). The Beck Depression Inventory, Center for Epidemiological Studies Depression Scale (CES-D), and General Well-Being Schedule Depression Subscale in Rheumatoid Arthritis: Criterion contamination of responses. Arthritis Care and Research, 4, 3-10.

Cassileth, B.R., Lusk, E.J., Strouse, T.B., Miller, D.S., Brown, L.L., Cross, P.A. and Tenaglia, A.N. (1984). Psychosocial status in chronic illness. A comparative analysis of six diagnostic groups. The New England Journal of Medicine, 311, 506-511.

Chamberlain, M.A., Buchanan, J.M. and Hanks, H. (1979). The arthritic in an urban environment. Annals of the Rheumatic Diseases, 38, 51-56.

Cornelissen, P.G.J., Rasker, J.J. and Valkenburg H.A. (1988). The arthritis sufferer and the community: a comparison of arthritis sufferers in rural and urban areas. Annals of the Rheumatic Diseases, 47, 150-156.

DiMatteo, M.R. and DiNicola, D.D. (1982). Achieving Patient Compliance, New York: Pergamon Press.

Doeglas, D.M., Suurmeyer, Th.P.B.M., Krol, B., Sanderman, R., Rijswijk, M.H. van and Leeuwen, M.L. van. (1992). Social support, social network and disability in relation to the duration of rheumatoid arthritis. Presented at IVth International Symposium for Health Professionals in Rheumatology, Harrogate, United Kingdom, June 10-12.

Ewart, C.K., Taylor, C.B., Reese, L.B. and Debusk, R.F. (1983). Effects of early postmyocardial infarction exercise testing on self-perception and subsequent physical activity. The American Journal of Cardiology, 5I, 1076-1080.

Feinberg, J. (1988). The effect of patient-practitioner interaction on compliance: A revicw of the literature and application in rheumatoid arthritis. Patient Education and Counseling, 11, 171-187.

Gonzalez, V.M., Goeppinger, J. and Lorig, K. (1990). Four psychosocial theories and their application to patient education and clinical practice. Arthritis Care and Research, 3, 132-143.

Goodenow, C., Reisine, S.T. and Grady, K.E. (1990). Quality of social support and associated social and psychological functioning in women with rheumatoid arthritis. Health Psychology, 9, 266-84.

Green, L.W. and Kreuter, M.W. (1991). Health promotion plan- ning, an educational and environmental approach. Mountain View, California: Mayfield.

Krol, B., Sanderman, R. and Suurmeijer, Th.P.B.M. (1993). Social support, rheumatoid arthritis and quality of life: concepts, measurement and research. Patient Education and Counseling, this issue.

Ley, Ph. (1979). Giving information to patients. In: Eiser, J.R. Social Psychology and Behavioral Medicine, New York: Wiley, 339-373.

Liang, M.H., Rogers, M., Larson, M., Eaton, H.M., Murawski, B.J., Taylor, J.E., Swafford, J. and Schur, P.H. (1984). The psychosocial impact of systemic lupus erythematosus and rheumatoid arthritis. Arthritis and Rheumatism, 27, 13-19.

Lorig, K., Chastain, R., Ung, E., Shoor, S. and Holman, H.R. (1989). Development and evaluation of a scale to measure the perceived self-efficacy of people with arthritis. Arthritis and Rheumatism, 32, 37-44.

Lorig, K.R., Cox, T., Cuevas, Y., Kraines, R.G. and Britton, M.C. (1984). Converging and diverging beliefs about arthritis: Caucasian patients, Spanish speaking patients, and physicians. Journal of Rheumatology, 11, 76-79.

Lorig, K., Konkol, L. and Gonzalez, V. (1987). Arthritis patient education: A review of the literature. Patient Education and Counseling, 10, 207-252.

Meenan, R.F., Gertman, P.M. and Mason, J.H. (1980). Measuring health status in arthritis - The Arthritis Impact Measurement Scales. Arthritis and Rheumatism, 23, $146-152$

Meenan, R.F., Gertman, P.M., Mason, J.H. and Dunaif, R. (1982). The arthritis impact measurement scales - further investigations of a health status measure. Arthritis and Rheumatism, 25, 1048-1053.

Meenan, R.F., Yelin, E.H., Henke, C.J., Curtis, D.L. and Epstein, W.V. (1978). The costs of rheumatoid arthritis: A patient-oriented study of chronic disease costs. Arthritis and Rheumatism, 21, 827-833.

Meenan, R.F., Yelin, E.H., Nevitt, M. and Epstein, W.V. (1981). The impact of chronic disease. A sociomedical profile of Rheumatoid Arthritis. Arthritis and Rheumatism, 24, 544-9.

Moos, R.H. and Solomon, G.F. (1964). Minnesota multiphasic personality inventory response patterns in patients with rheumatoid arthritis. Journal Psychosomatic Research, 8 , 17-28.

O'Leary, A., Shoor, S., Lorig, K. and Holman, H.R. (1988). A cognitive behavioral treatment for rheumatoid arthritis. Health Psychology, 7, 527-544.

Peck, J.R., Smith, T.W., Ward, J.R. and Milano, R. (1989). Disability and depression in rheumatoid arthritis. A multitrait, multi-method investigation. Arthritis and Rheumatism, $32,1100-1106$.

Pincus, T. and Callahan, L.F. (1993). Depression scores in rheumatoid arthritis: Criterion contamination of patient responses. Patient Education and Counseling, this issue

Pincus, T., Callahan, L.F., Bradley, L.A., Vaughn, W.K. and Wolfe, F. (1986). Elevated MMPI scores for hypochon- 
driasis, depression, and hysteria in patients with rheumatoid arthritis reflect disease rather than psychological status. Arthritis and Rheumatism, 29, 1456-1466.

Rasker, J.J., Bronner, A.E. and Verzijden, D. (1984). Reuma hebben. Wat het betekent reumatoïde arthritis patiënt te zijn. Etten Leur: Lederle Nederland B.V.

Rasker, J.J. and Cosh, J.A. (1987). The natural history of rheumatoid arthritis over 20 years. Clinical symptoms, radiological signs, treatment, mortality and prognostic significance of early features. Clinical Rheumatology, 6 (Suppl. 2), 5-11.

Riemsma, R.P., Taal, E., Brus, H., Wiegman, O. and Rasker, J.J. (1992). Individual education to people with rheumatoid arthritis. Clinical Rheumatology, 11, 298.

Ropes, W.M., Bennett, G.A., Cobb, S., Jacox, R. and Jessar, R.A. (1958). The 1958 revision of diagnostic criteria for rheumatoid arthritis. Bulletin of Rheumatic Diseases, 9 , 175-176.

Ruddy, S. (1985). The management of rheumatoid arthritis. In W.N. Kelley, E.D. Harris, S. Ruddy, C.B. Slcdge (Eds.). Textbook of Rheumatology. Vol. I, 2nd edition. (pp. 979-992). Philadelphia: W.B. Saunders Comp.

Shoor, S.M. and Holman, H.R. (1984). Development of an instrument to explore psychological mediators of outcome in chronic arthritis. Transactions of the Association of American Physicians, 97, 325-331.

Spergel, P., Ehrlich, G.E. and Glass, D. (1978). The rheumatoid arthritic personality: a psychodiagnostic myth. Psychosomatics, 19, 79-86.

Steinbröcker, O., Traeger, C.H. and Batterman, R.C. (1949). Therapeutic criteria in rhcumatoid arthritis. Journal of the American Medical Association, 140, 659-662.

Taal, E., Jacobs, J.W., Seydel, E.R., Wiegman, O. and Rasker, J.J. (1989). Evaluation of the Dutch arthritis impact measurement scales (DUTCH-AIMS) in patients with rheumatoid arthritis. British Journal of Rheumatology, 28, 487-491.

Taylor, C.B., Bandura, A., Ewart, C.K., Miller, N.H. and DeBusk, R.F. (1985). Exercise testing to enhance wives' confidence in their husbands' capabilities soon after clinically uncomplicated acute myocardial infarction. American Journal of Cardiology, 55, 635-638.

Weinberger, M., Tierney, W.M., Booher, P. and Hiner, S.L. (1990). Social support, stress and functional status in patients with osteoarthritis. Social Science and Medicine, 30, 503-508.

Correspondence to: Erik Taal, MA, Department of Psychology, University of Twente, P.O. Box 217, 7500 AE Enschede, Netherlands. 